\title{
Os efeitos das manifestações, segundo a população em geral
}

Para a maior parte dos entrevistados, as revoltas de junho tiveram como alvo os políticos em geral.

Os dados também mostram que $45 \%$ estão mais otimistas com o futuro do Brasil após os protestos, mas em torno do mesmo percentual acredita que haverá apenas poucas mudanças na atuação dos políticos e para o país.
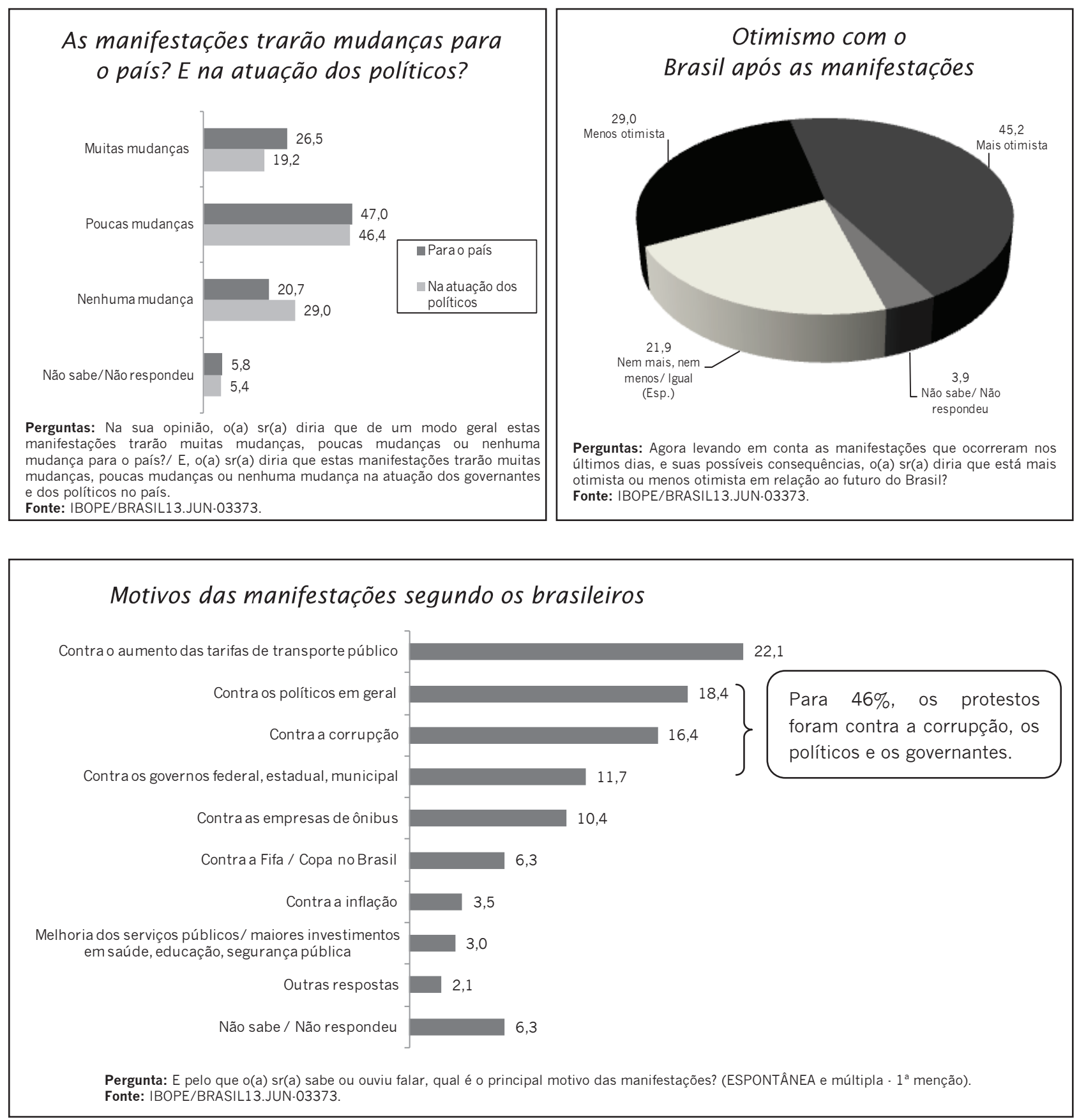

OPINIÃO PÚBLICA, Campinas, Vol. 19 nº 2, novembro, 2013, Encarte Tendências. p.475-485 


\section{O apoio às manifestações entre a população em geral}

Quase $80 \%$ dos entrevistados apoiam os protestos que ocorreram em várias cidades brasileiras.

Entre os contrários às manifestações destacam-se um maior percentual de mulheres, com mais de 40 anos e os de menores renda e escolaridade (até 2 salários mínimos e Ensino Fundamental incompleto).
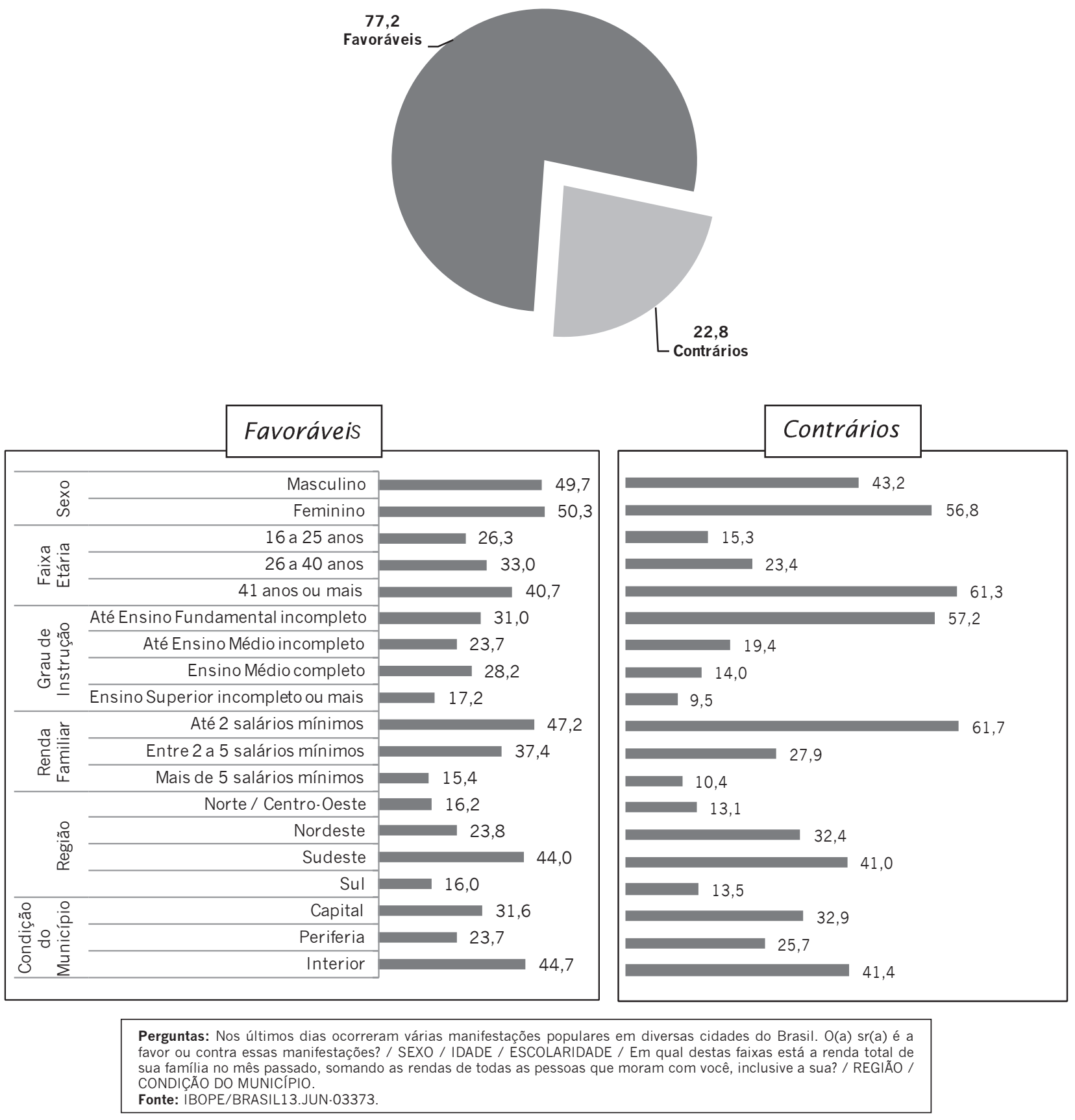


\section{A eficácia das manifestações, segundo a população em geral}

Quase $60 \%$ dos entrevistados apontam as manifestações como meio mais adequado para cobrar a melhor atuação dos políticos e a oferta de políticas públicas.

Quando os resultados são estratificados por sexo, faixa etária e grau de instrução, o que se destaca é que apenas esta última variável distingue mais os entrevistados, com aqueles que cursaram, no máximo, o Ensino Fundamental incompleto, com percepções divididas sobre a eficácia das manifestações e outros meios para exigir melhores políticas públicas.

As manifestações são a melhor maneira de cobrar melhoria na ação dos políticos e governantes?
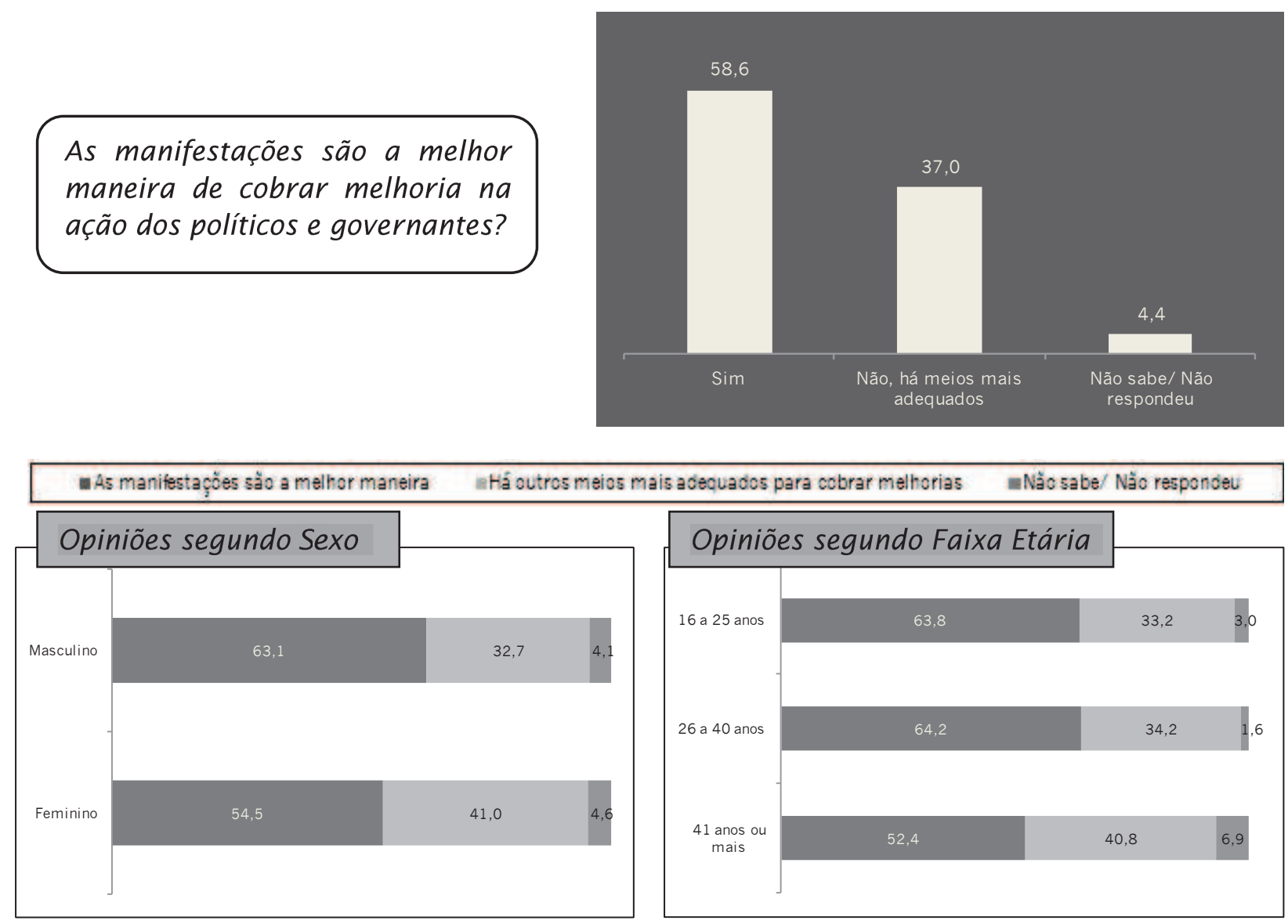

Opiniões segundo Grau de Instrução

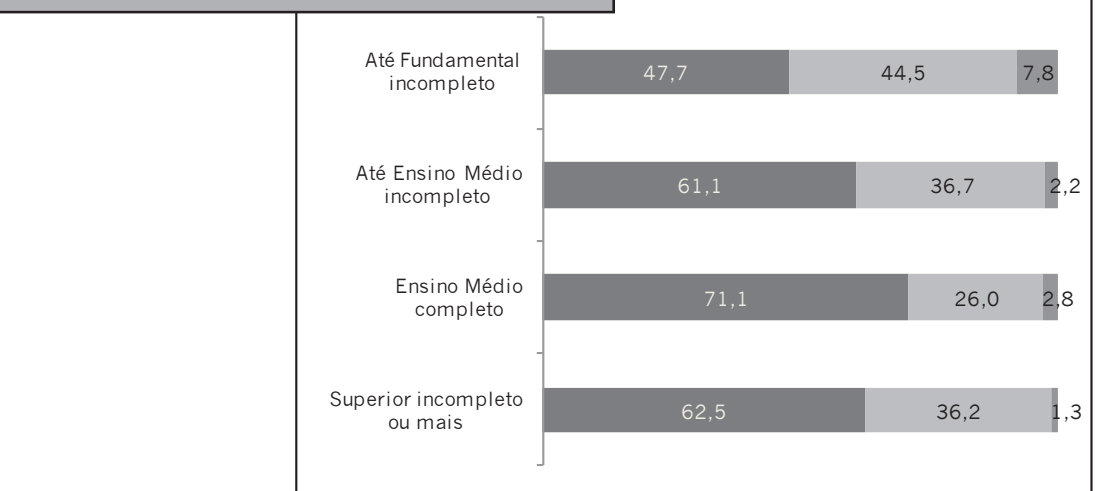

Perguntas: Na sua opinião, as manifestações que ocorreram nos últimos dias, são a melhor forma que existe ou há outros meios mais adequados para cobrar melhorias nas políticas públicas e na atuação dos governantes e políticos em geral? / IDADE / ESCOLARIDADE.

Fonte: IBOPE/BRASIL13.JUN-03373. 


\section{A percepção da violência nas manifestações segundo a população em geral}

Pouco mais de $40 \%$ dos entrevistados acreditam que houve violência nas manifestações não apenas por parte da polícia, mas também dos manifestantes.

Os menos escolarizados (até Ensino Fundamental incompleto) são os que mais apontam a violência excessiva dos manifestantes. Com relação à violência policial, são os mais jovens (16 a 25 anos) os que mais apontam que ela foi exagerada.
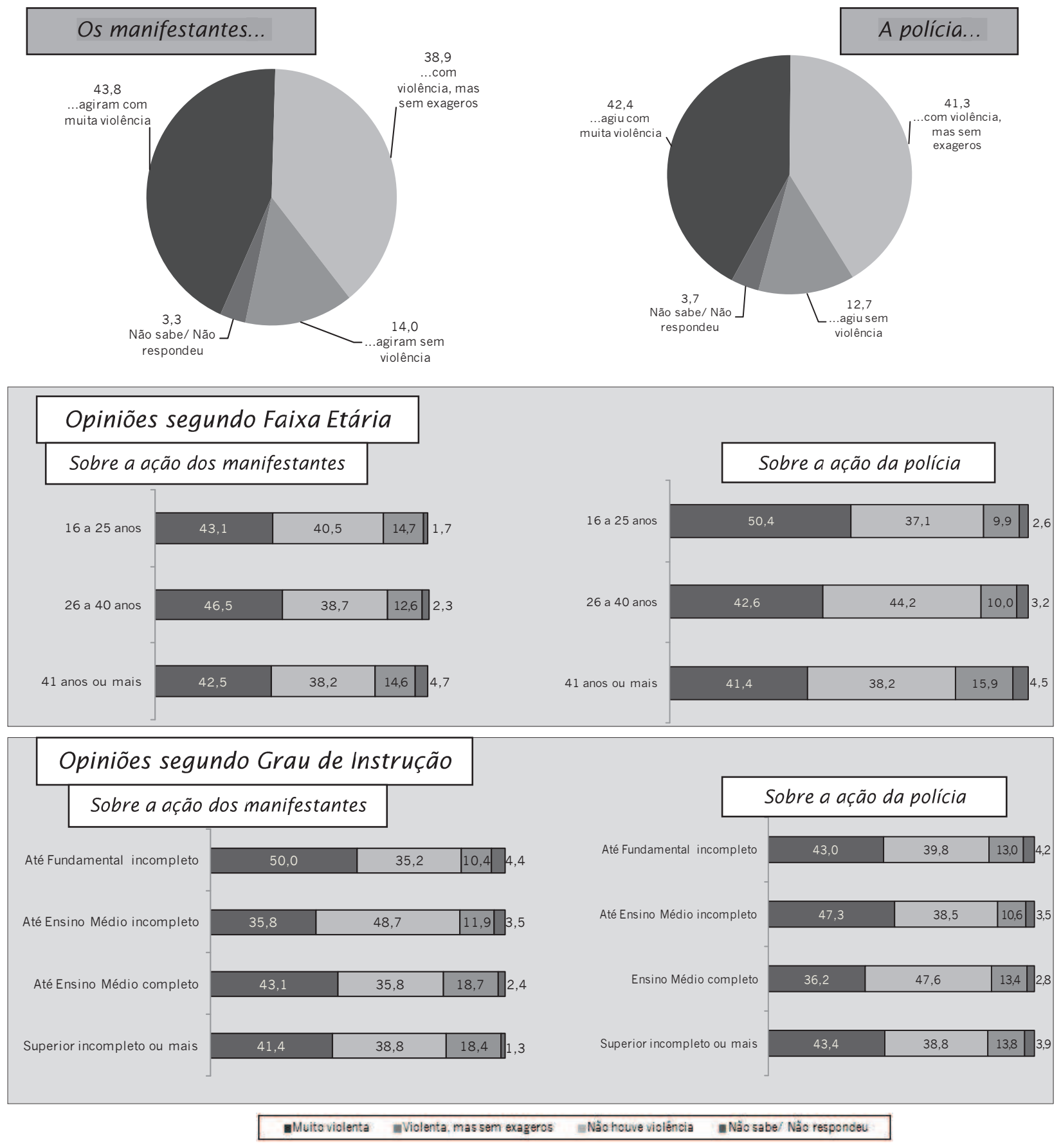

Perguntas: Pensando na atuação dos manifestantes durante as manifestações, o(a) sr(a) diria que de modo geral os manifestantes: / IDADE / ESCOLARIDADE. E pensando na atuação da polícia para conter as manifestações, o(a) sr(a) diria que de modo geral a polícia: / IDADE / ESCOLARIDADE.

Fonte: IBOPE/BRASIL13.JUN.03373.

Tendências 480

OPINIÃO PÚBLICA, Campinas, Vol. 19 nº 2, novembro, 2013, Encarte Tendências. p.475-485 
Manifestantes

da cidade de São Paulo

\section{Quem são os manifestantes da cidade de São Paulo?}

As características socioeconômicas dos manifestantes que ocuparam a Avenida Paulista em junho deste ano mostram não apenas a elevada concentração de jovens (16 a 25 anos), mas as altas escolaridade e renda dos manifestantes, quando comparados à população geral da cidade de São Paulo.
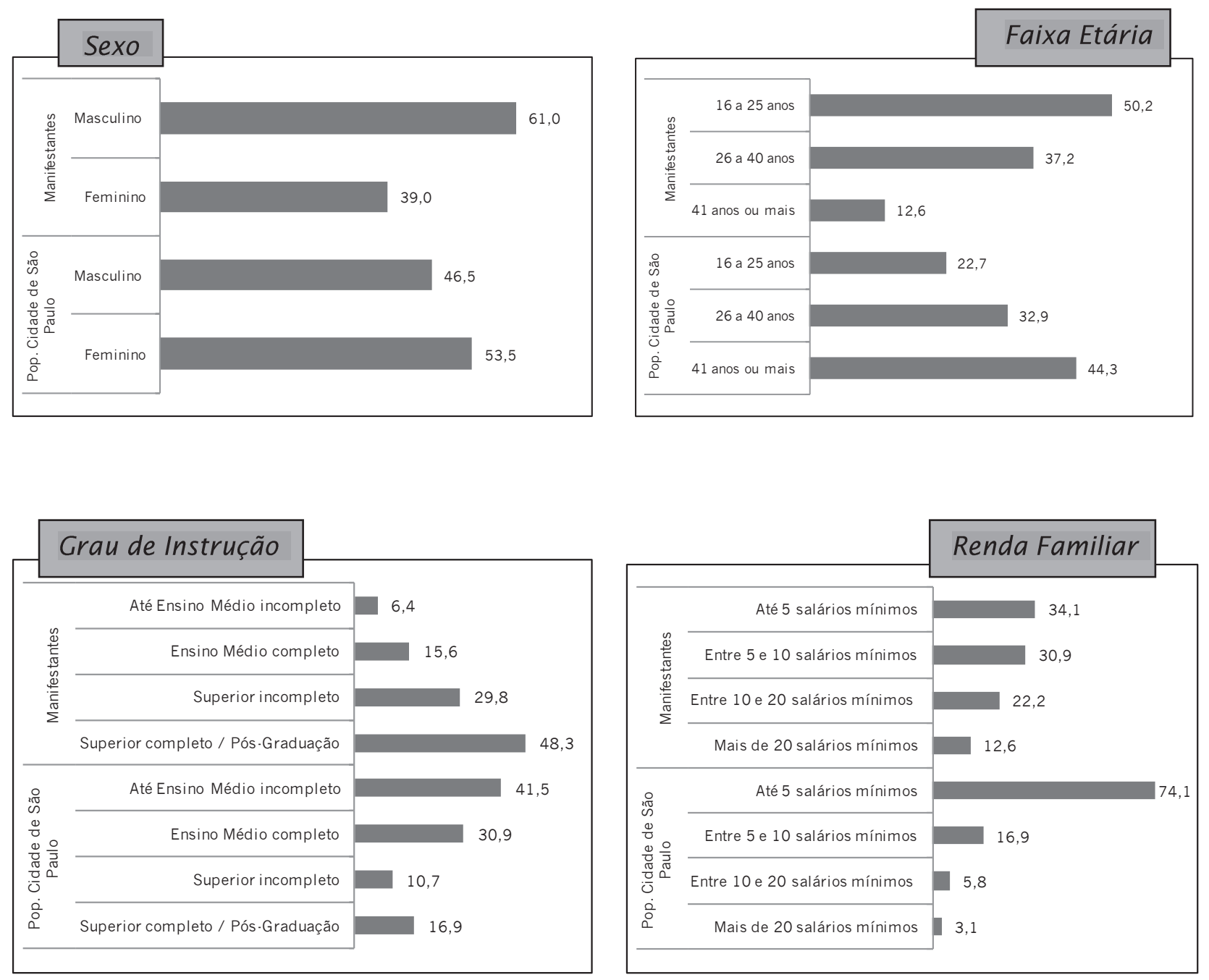

Perguntas: SEXO / Qual a sua idade / Até que ano da escola você estudou? / Somando a sua renda com a renda de todas as pessoas que moram com você, quanto é aproximadamente a renda familiar na sua casa?

Fontes: DATAFOLHA/SÃOPAULO13.JUN-03375; DATAFOLHA/SÃOPAULO13.JUN-03377.

OPINIÃO PÚBLICA, Campinas, Vol. 19 n², novembro, 2013, Encarte Tendências. p.475-485 Tendências 481 


\section{Adesão às manifestações}

Mais de $90 \%$ dos entrevistados afirmaram terem ido às ruas a partir da mobilização pelas redes sociais.

A maioria dos manifestantes já havia participado de outros protestos contra o aumento das passagens na cidade de São Paulo. Quando perguntados sobre o motivo de estarem nas ruas, os manifestantes mencionaram lutar não apenas contra o aumento das passagens, mas também contra a corrupção e os políticos.

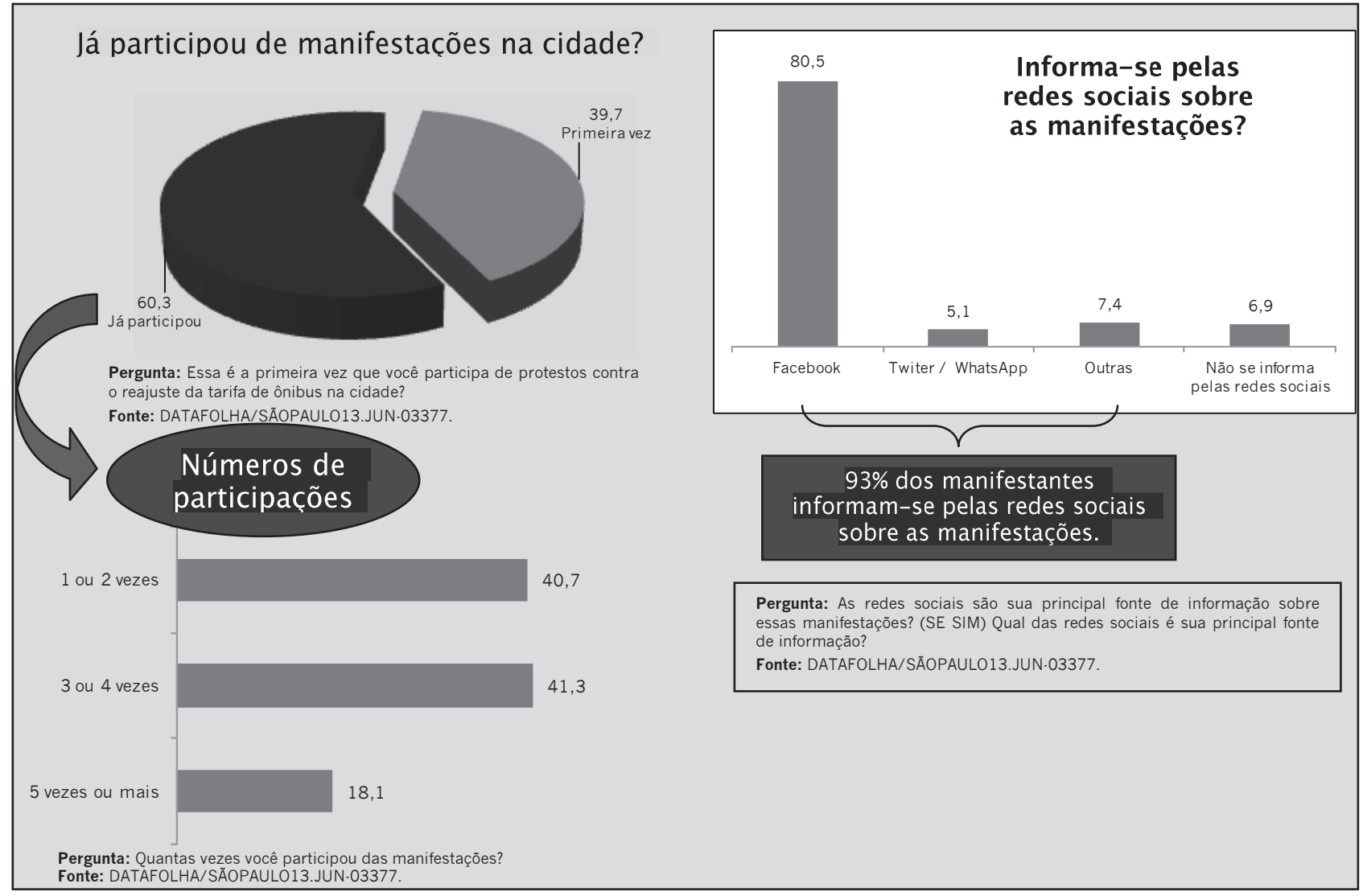

Motivos das manifestações segundo os manifestantes

da Paulista e segundo os Paulistanos em geral

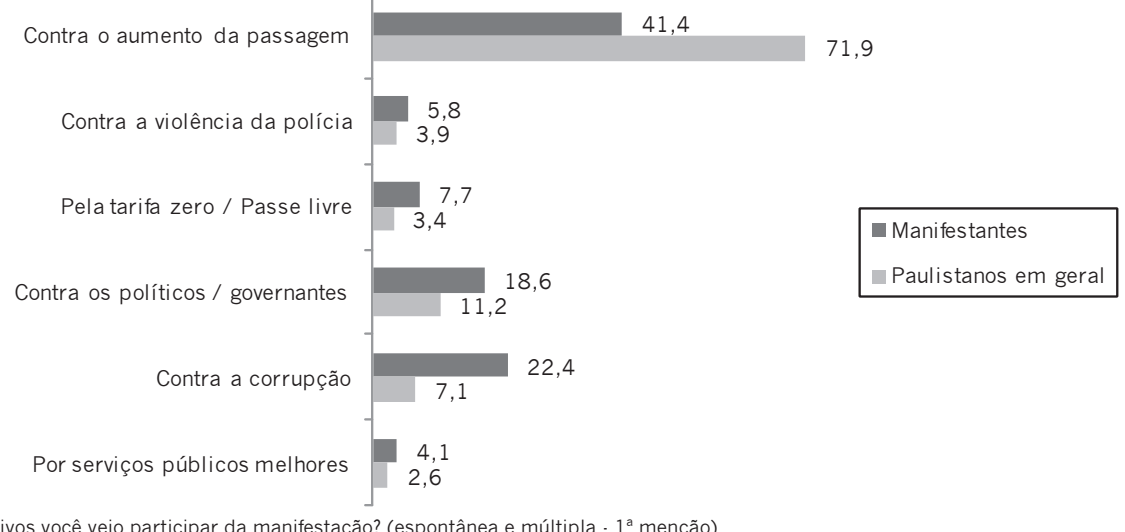

Perguntas: Por quais motivos você veio participar da manifestação? (espontânea e múltipla $\cdot 1^{\text {a }}$ menção).

Ontem aconteceu uma manifestação na cidade de São Paulo que reuniu cerca de 65 mil pessoas. Na sua opinião, por quais motivos essas pessoas participaram dessa manifestação? (espontânea e múltipla $\cdot 1^{\mathrm{a}}$ menção).

Fonte:DATAFOLHA/SÃOPAULO13.JUN.03375; DATAFOLHA/SÃOPAULO13.JUN.03377.

Tendências 482 OPINIÃO PÚBLICA, Campinas, Vol. 19 nº 2, Novembro, 2013, Encarte Tendências. p.475-485 
Manifestantes

da cidade de

São Paulo

\section{Eficácia de formas de ação política}

Pelo menos $70 \%$ dos manifestantes entrevistados acreditam na eficácia de fazer greves, participar de plebiscitos e assinar abaixo-assinados. Por outro lado, apenas $20 \%$ deles pensam que participar de um partido político é um modo eficaz de ação política.

Corroborando o alto papel mobilizador das redes sociais apontado pelos manifestantes, é notável que mais de $80 \%$ acreditem na eficácia da internet como espaço de discussão política.

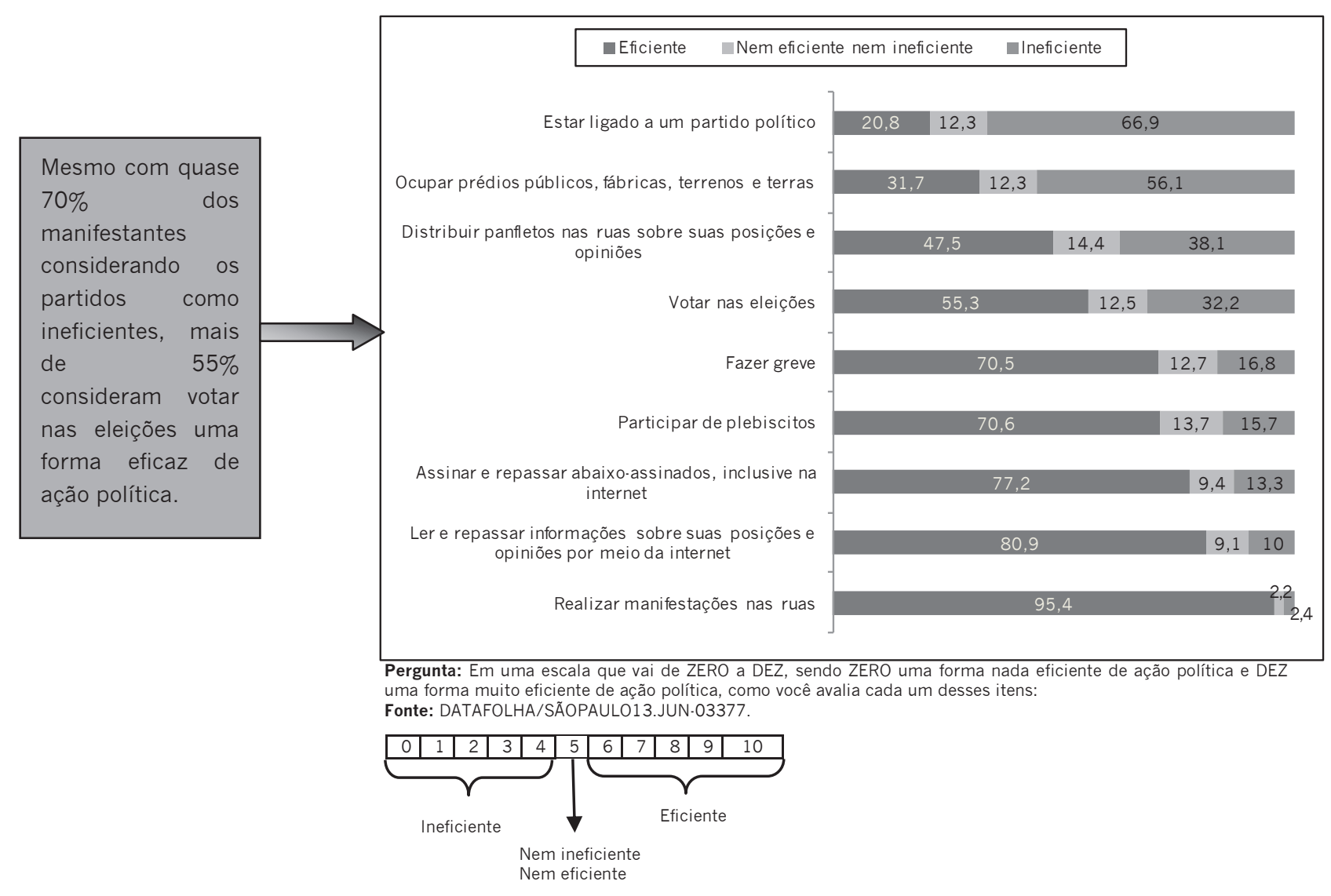




\section{$\%$ \\ Forma de Representação e Preferências Políticas}

Manifestantes

da cidade de

São Paulo

A maioria dos manifestantes de junho de 2013 é contra o voto obrigatório, não tem preferência por partido político e acredita que os sindicatos servem mais para fazer política do que defender os interesses dos trabalhadores. Com relação ao autoposicionamento ideológico, os manifestantes dividem-se sobretudo entre a esquerda e o centro.
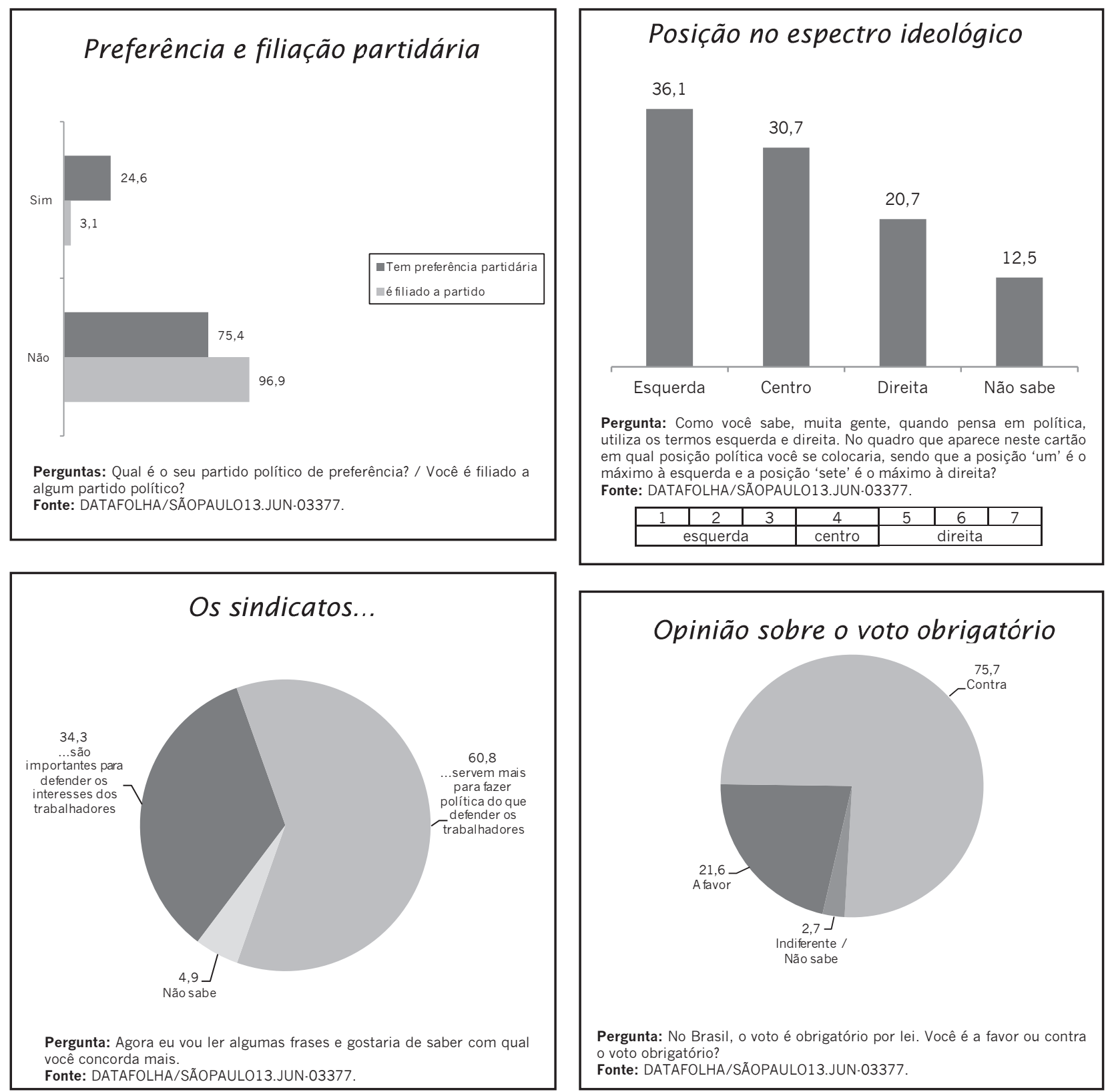

Tendências 484

OPINIÃO PÚBLICA, Campinas, Vol. 19 n², novembro, 2013, Encarte Tendências. p.475-485 